\title{
Article \\ Early Shoot Development Affects Carbohydrate Supply and Fruit Quality of Red-Fleshed Actinidia chinensis var. chinensis 'Zes008'
}

\author{
Annette Richardson ${ }^{1, *}$, Victoria Eyre ${ }^{1}$, Peggy Kashuba ${ }^{1}$, Deborah Ellingham ${ }^{1}$, Heather Jenkins ${ }^{2}$ and \\ Simona Nardozza ${ }^{3}$ (D) \\ 1 Kerikeri Research Centre, The New Zealand Institute for Plant \& Food Research Limited (PFR), \\ 121 Keri Downs Road, RD1, Kerikeri 0294, New Zealand; victoria.eyre@plantandfood.co.nz (V.E.); \\ peggy.kashuba@plantandfood.co.nz (P.K.); deborah.ellingham@plantandfood.co.nz (D.E.) \\ 2 Lincoln Research Centre, PFR, Private Bag 4704, Christchurch Mail Centre, Christchurch 8140, New Zealand; \\ heather.jenkins@plantandfood.co.nz \\ 3 Mt Albert Research Centre, PFR, Private Bag 92169, Auckland 1142, New Zealand; \\ simona.nardozza@plantandfood.co.nz \\ * Correspondence: annette.richardson@plantandfood.co.nz
}

check for updates

Citation: Richardson, A.; Eyre, V.; Kashuba, P.; Ellingham, D.; Jenkins, H.; Nardozza, S. Early Shoot Development Affects Carbohydrate Supply and Fruit Quality of Red-fleshed Actinidia chinensis var. chinensis 'Zes008'. Agronomy 2021, 11, 66. https://doi.org/10.3390/ agronomy11010066

Received: 30 November 2020 Accepted: 29 December 2020 Published: 30 December 2020

Publisher's Note: MDPI stays neutral with regard to jurisdictional clai$\mathrm{ms}$ in published maps and institutional affiliations.

Copyright: (C) 2020 by the authors. Licensee MDPI, Basel, Switzerland. This article is an open access article distributed under the terms and conditions of the Creative Commons Attribution (CC BY) license (https:// creativecommons.org/licenses/by/ $4.0 /)$.

\begin{abstract}
Fruit quality characteristics are highly variable across kiwifruit vines due to complex source-sink interactions. We investigated how variation in fruit quality of Actinidia chinensis (Planch.) var. chinensis 'Zes008' was influenced by different shoot types (short, medium or long) and rootstocks types (Actinidia chinensis (Planch.) var. deliciosa (A. Chev.) 'Bruno' or Actinidia macrosperma C.F. Liang). Short shoots had smaller leaves $(-30$ to $-50 \%)$ and lower photosynthesis rates $(-0.70$ to $-3.34 \mu \mathrm{mol} \mathrm{m}^{-2} \mathrm{~s}^{-1}$ ) in the first cluster of nine leaves (Zone 1) compared with leaves on medium or long shoots. Later in the season, photosynthesis rates in Zone 1 declined with leaf age, but photosynthesis rates were higher $\left(+0.5\right.$ to $\left.+6.1 \mu \mathrm{mol} \mathrm{m}^{-2} \mathrm{~s}^{-1}\right)$ in later developing leaves on medium or long shoots. Fruit from short shoots had lower dry matter ( -0.3 percent units) and lower outer pericarp flesh red pigment scores than fruit from medium or long shoots. At harvest, fruit from vines on 'Bruno' rootstocks were larger $(+3.7 \mathrm{~g})$, had higher dry matter $(+1.3$ percent units), soluble solids concentration $\left(+1.7^{\circ}\right.$ Brix) and firmness $(+0.4 \mathrm{kgf})$ than fruit from vines on $A$. macrosperma rootstocks. Factors that prioritised early development of source leaves had a direct impact on the carbohydrate supply from photosynthesis to support flower and fruit development.
\end{abstract}

Keywords: flesh colour; kiwifruit; leaf area; photosynthesis; rootstock; shoot type

\section{Introduction}

Consumers want fruit and vegetables to fit their desire for a 'perfect' product [1,2]. They use aesthetic cues such as fruit size, shape, skin colour, freedom from external blemish [3,4] as well as perceived health benefits [5] as selection criteria when purchasing fruit. However, consumer satisfaction with fruit is driven by intrinsic internal quality characteristics such as flavour, texture and freedom from internal defects that are only evident when fruit are consumed [6]. Variability in fruit quality parameters contributes to the perception of many consumers that purchasing good quality fruit occurs by chance [1] and poor consumer experiences reduce the likelihood of consumers making repeat purchases [7]. Up to one-third of all food being wasted in the home is linked to consumer uncertainty around the quality of purchased fruit [8].

Studies of environmental [9-12], genetic [13,14] and cultural practices [15,16] effects on fruit traits (external and internal) have mainly focused on changes to the mean value of fruit quality attributes across experimental units such as plants. Only a small number of more recent studies have shown that differences in fruit quality characteristics within plants can also be large [17-19]. 
Differences in fruit quality within plants is influenced by the dynamics of sourcesink relationships [20]. Differences in fruit sink efficiency have been linked to variable carbohydrate supply to sinks, competition between sinks and variable metabolic activity within fruit sinks. Many factors can affect carbohydrate supply to fruit including the position of the fruit within the canopy in relation to either source leaves or competing fruit [21-23] as well as leaf light exposure $[9,24,25]$. Competition can occur between fruit sinks $[26,27]$ or between fruit and vegetative sinks [28,29]. Differences in the metabolic activity of fruit sinks has also been reported in both peaches [30] and the red-fleshed Actinidia chinensis var. chinensis 'Zes006' [31].

In vine crops, such as grape and kiwifruit, that have a long period of leaf development before flowering, variation in berry size $[19,32]$ and berry quality $[18,19]$ originates before berry set. However in plum, a drupe produced on a tree that flowers before leaf development, fruit size variation is determined during post bloom cell division [33]. In deciduous fruiting crops flowering immediately after dormancy (e.g., plum and peaches), fruit photosynthesis during early developmental stages makes an important contribution to fruitlet carbohydrate reserves [34]. This suggests that although the exact timing of key phenological events may vary between different fruit crops, there is a period during early fruit development that is very sensitive to carbohydrate supply.

In many fruit crops carbohydrate supply from photosynthesis (source strength) may vary through factors such as leaf area, leaf position, light exposure and leaf age, and this can have significant effects on the amount of photosynthate supplied to fruit sinks. In both kiwifruit and grape, the vine must support both rapid canopy and flower development over the long lag period between budbreak and flowering [35,36]. During this period vines rely heavily on previously stored reserves to support new growth $[37,38]$ and shoots do not become autotrophic until at least 40 days after budbreak [28,39].

In kiwifruit vines, all dormant axillary buds of a 1-year-old cane (Figure 1A) have the potential to become long non-terminated shoots (also defined as proleptic). However, factors that restrict rapid growth of preformed nodes can cause shoot tip abortion and termination of shoot growth [40]. This causes variation in shoot type within the canopy of kiwifruit vines. Three shoot categories (for proleptic shoots) have been defined by Seleznyova et al. [41] (Figure 1A,B): short shoots produce up to nine nodes and are terminated; medium shoots have between 10 and 18 nodes, and are terminated; long shoots have more than 18 nodes and may have up to 90 nodes, and are non-terminated. Kiwifruit dormant axillary buds have a set number of preformed leaf primordia [35], but neoformed leaf primordia can form subsequently during shoot development [42]. Seleznyova et al. [42] defined different leaf Zones along A. chinensis var. deliciosa 'Hayward' shoots according to the origin of the leaf primordia and the timing of its development (Figure 1B). Zone $1(<10$ leaves) includes up to the first nine leaves from the preformed leaf primordia developing from budbreak and it is present in all shoot types. Zone 2 (10-18 leaves) includes the distal nine leaves from the preformed leaf primordia expanding later than Zone 1 leaves and it is present in medium and long shoots. Zone 3 (>18 leaves) includes the neoformed leaves from the nineteenth leaf onwards and it is only present in the long shoots. Rootstock vigour can influence shoot growth, as shoots on vines grafted onto less vigorous rootstocks are more likely to terminate and produce short shoots than shoots on vines with more vigorous rootstocks [43]. Recent research in red-fleshed kiwifruit has linked both the effects of rootstock and shoot type to variation in fruit properties at harvest [17].

The aim of this study was to examine more closely the growth and photosynthetic performance of different shoot types within vines and with different rootstocks between vines of a red-fleshed A. chinensis var. chinensis 'Zes008' throughout the growing season. These differences in shoot properties were then related to variation in fruit quality at harvest. We quantified how the seasonal pattern of shoot development on vines with two different rootstocks affected the ability of leaves to support fruit development. Our hypothesis was that there is less carbohydrate supply from leaves to fruit on short shoots regardless of 
rootstock type and across all shoot types from vines on A. macrosperma rootstock, both of which contribute to differences in fruit quality at harvest.
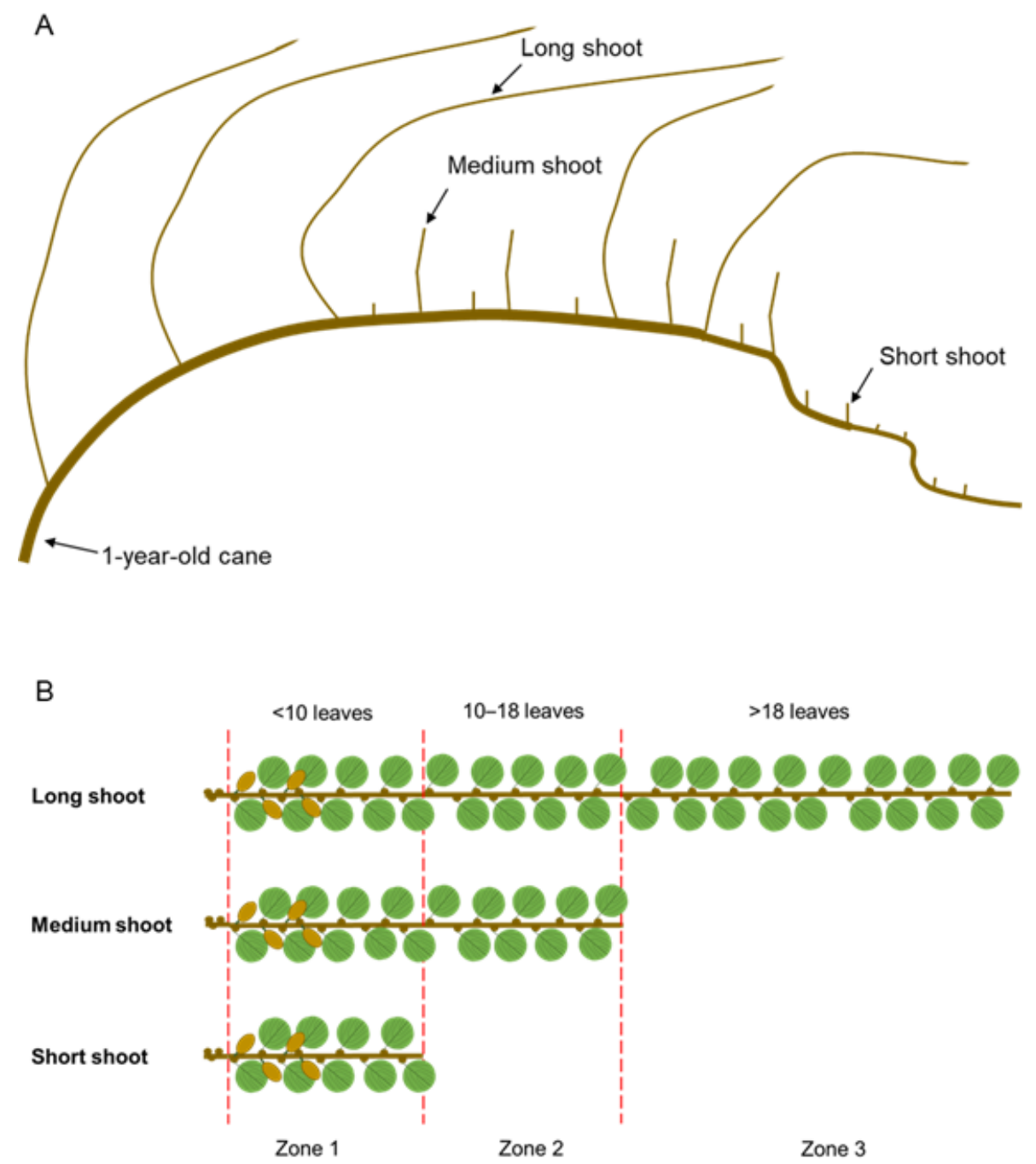

Figure 1. Schematic representation of Actinidia spp. branching patterns. (A) 1-year-old cane, lignified, with examples of three different shoot types (long, medium and short; redrawn from Seleznyova et al. [41]); (B) detailed representation of the three shoot types (new growth from dormant buds, fruiting) and subdivision of the shoots into the Zones according to the number of leaves (based on data from Seleznyova et al. [42]).

\section{Materials and Methods}

\subsection{Plant Material}

This experiment was carried out on vines of the red-fleshed Actinidia chinensis (Planch.) var. chinensis 'Zes008' cultivar, which has a block-red (red inner and outer pericarp) flesh colour. Vines were grafted onto either 10-year-old A. chinensis (Planch.) var. deliciosa (A. Chev.) 'Bruno' seedling or 10-year-old A. macrosperma C.F. Liang clonal rootstocks in 2015. Vines were spaced $3.6 \mathrm{~m}$ by $3.0 \mathrm{~m}$ apart in a commercial orchard in Kerikeri, New Zealand $\left(35^{\circ} 10^{\prime} \mathrm{S} 173^{\circ} 55^{\prime} \mathrm{E}\right)$ which included male pollinator vines. The vines were trained on a pergola system with a combination of 1-year-old cane and older wood laid down in winter to form the basis of the canopy for the following season. All vines were managed using standard commercial practices [44] including regular irrigation with mini-sprinklers. Vines were thinned to a crop load of c. 50 fruit per square metre and trunk girdled twice: once during rapid fruit growth (18 December 2018, 53 days after anthesis, DAA) and once during fruit dry matter accumulation (23 January 2019, 89 DAA). Vines on A. macrosperma 
rootstocks reached $50 \%$ budbreak on 10 September 2018 and four days later on vines on 'Bruno' rootstocks. All vines reached 50\% flowering (anthesis) on 26 October 2018. Fruit were harvested from vines on 8 April 2019 (168 DAA).

\subsection{Experimental Design}

The effects of shoot type and rootstock on shoot development, gas exchange and fruit quality were determined using a split plot experimental design. Whole vines on either 'Bruno' or A. macrosperma rootstocks were the main plots, whilst shoot types were used as subplots. Measurements of shoot development and gas exchange were made on four vines on each rootstock (biological replicates). Two shoots of each type (short, medium and long) were randomly selected on each vine (one on each side of each vine) soon after budbreak (when differences between shoots were evident), labelled and maintained in full sunlight throughout the season. All selected shoots were floral at the time of selection and set fruit afterwards. Shoot types were defined according to the three categories from Seleznyova et al. [41]: short shoots were terminated with $<10$ leaves, medium shoots were terminated with 10-18 leaves and long shoots were not terminated and had >18 leaves. Early in the growing season (three weeks after budbreak), shoot types were selected according to the vigour of internode extension and the appearance of the shoot apex. Fifty shoots of each shoot type were randomly selected from a total of 10 vines of each rootstock (the four vines used for shoot measurements and six adjacent vines) soon after flowering and tagged for fruit quality assessments. At commercial harvest (168 DAA), the first two fruit at the proximal end of the shoot were sampled. Fifteen fruit were also sampled from vines on 'Bruno' rootstocks at two-weekly intervals to describe changes in fruit quality during development.

\subsection{Shoot Measurements}

Length, basal diameter and leaf number of each shoot and the maximum width and length (measured along the mid-rib) of all leaves on each shoot were measured at fourweekly intervals throughout the growing season. Average internode length was calculated from shoot length and leaf number. Shoots were divided into zones, with the initial cluster of leaves (<10 leaves) in Zone 1 for all shoot types, while medium and long shoots also produced leaves from the remaining preformed leaf initials in Zone 2 (10-18 leaves) and long shoots initiated new leaves in Zone 3 (>18 leaves) [42]. The diameter at the base of the cane and at the cane at the base of shoots were measured for all shoots that fruit were harvested from.

Leaf area was determined using a linear regression fit between the product of leaf lamina width and length and measured leaf area. Measurements were made on 120 leaves of varying size that were randomly selected for vines on each rootstock type at a single time point in December. Measured leaf dimensions were converted to leaf area estimates using the coefficients established by obtaining the line of best fit between measured leaf area (LI3100 Li-Cor, Lincoln, NE, USA) and the product of maximum leaf width and length along the main vein. A previous study reported the relationship between leaf area and leaf diameter for 'Hayward' kiwifruit [45] and a linear relationship between the product of leaf dimensions and measured leaf area has been shown for a number of other crops including grape [46].

\subsection{Gas Exchange}

Gas exchange rates were measured on every second leaf along selected shoots at 4-weekly intervals using a Li-Cor 6400 open path photosynthesis system (Li-Cor Inc., Lincoln, NE, USA) fitted with a carbon dioxide $\left(\mathrm{CO}_{2}\right)$ mixer. The $\mathrm{CO}_{2}$ concentration was set at $400 \mu \mathrm{mol} \mathrm{mol}^{-1}$ at the leaf surface, the 6400-02B LED light source was set at $1500 \mu \mathrm{mol} \mathrm{m}{ }^{-2} \mathrm{~s}^{-1}$ and measurements were made under ambient temperature and vapour pressure deficit conditions. All gas exchange measurements on experimental shoots were made between 10.00 and $15.00 \mathrm{~h}[47,48]$. Leaves were enclosed in the chamber in situ at 
their normal orientation, readings were allowed to stabilise and then three consecutive measurements were made for each leaf.

\subsection{Fruit Measurements}

At commercial harvest (168 DAA), the two proximal fruit on each selected shoot were harvested and fruit were individually weighed. A 2- mm equatorial slice was taken from each fruit to determine the red pigment intensity and spread scores and to measure fruit dry matter. The visual red pigment intensity of both the inner and outer pericarp was measured using a scale of 0 to $5(0=$ absent; $5=$ very intense red $)$ and the spread of red pigment throughout the fruit pericarp tissues was also scored on a 0 to 5 scale $(0=$ no red pigmentation; 5 = red pigmentation spread throughout the pericarp) [49]. Dry matter of each fruit was determined gravimetrically, each fresh cut slice was weighed immediately and then oven-dried for $24 \mathrm{~h}$ at $65^{\circ} \mathrm{C}$ and the dry weight of the slice was recorded [50]. Dry matter was expressed as a percentage of dry weight vs. fresh weight. Photographs of each slice were taken prior to drying and used to count carpel number and to measure maximum and minimum equatorial diameter and the ratio (minimum diameter / maximum diameter) was used to determine how cylindrical fruit were.

Average soluble solids concentration (SSC) was measured using a hand-held optical refractometer (0-20\%, Atago, Tokyo, Japan) using juice squeezed from 10- mm slices from both the stylar and stem end of fruit, as SSC varies throughout the fruit [51]. Flesh firmness was assessed by a Fruit Texture Analyser (Güss model GS14, Strand, South Africa) with a $7.9 \mathrm{~mm}$ probe at $1 \mathrm{~mm}$ below the skin, with two measurements taken at the fruit equator at $90^{\circ}$ to each other [52].

\subsection{Statistical Analysis}

Statistical analysis was carried out using a linear mixed effects model (REML) in GenStat 17th edition for Windows (VSN International Ltd., Hemel Hempstead, Hertfordshire, UK). Pair-wise comparisons between mean values were made using least significant differences (LSD) at the appropriate level of significance ( $p$-values are presented in the text). The standard error of the mean (SEM) was calculated from the sample standard deviation $/ \sqrt{ }$ sample size. Linear regression between the product of leaf width and length and measured leaf area was carried out using Origin, Version 2019 (OriginLab Corporation, Northhampton, MA, USA).

To test the relationship between the shoot and fruit datasets, partial least squares (PLS) regression multivariate methodology was used [53]. PLS maximizes the covariance between components from two data sets. A linear combination of variables is called latent variables or latent components. The weight vectors used to calculate the linear combinations are called the loading vectors. Latent variables and loading vectors are thus associated and come in pairs from each of the two data sets being integrated. Sparse PLS (sPLS) was developed to perform simultaneous variable selection in both data sets $X$ and $Y$ data sets, by including LASSO penalizations in PLS on each pair of loading vectors. The sPLS analysis was performed in R 2020 (R foundation for Statistical Computing, Vienna, Austrai) [54] using the mixOmics package [55].

\section{Results}

\subsection{Estimation of Leaf Area from Linear Dimensions}

There was a strong linear relationship between the measured leaf area of 'Zes008' leaves and the product of the length and the maximum width of the leaf (Figure 2). Rootstock type did not have a significant effect on leaf shape or the relationship between leaf dimensions and leaf area, therefore all data were combined. The width of the leaf was approximately $28 \%$ greater than the leaf length. Examining the relationship between the 
product of leaf dimensions and leaf area, the intercept did not significantly differ from zero and therefore was removed, resulting in the Equation:

$$
\text { Leaf area }=0.899(\mathrm{~L} \times \mathrm{W}), \mathrm{r}^{2}=0.996
$$

where $\mathrm{L}=$ leaf length along the mid rib and $\mathrm{W}=$ leaf maximum width.

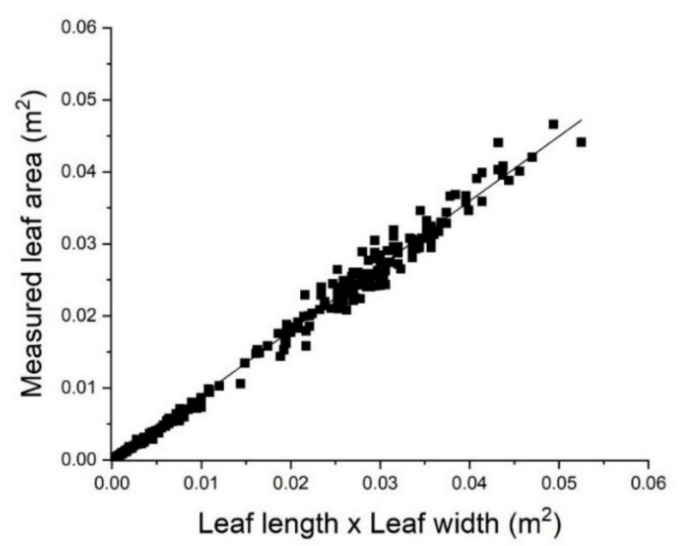

Figure 2. The relationship between leaf area and the product of leaf length measured along the mid rib and maximum leaf width of Actinidia chinensis var. chinensis 'Zes008' leaves, $n=240$. Leaf area $=$ $0.899(\mathrm{~L} \times \mathrm{W}), \mathrm{r}^{2}=0.996$.

\subsection{The Growth and Development of Shoots}

Differences in shoot characteristics across the rootstock $\times$ shoot type combinations were established during the early stages of shoot development (Figure 3). From soon after budbreak (in October) there were significant $(p<0.05)$ differences in the basal diameter of the three different shoot types, with small shoots having the smallest diameter and large shoots the greatest diameter (Figure 3A). These differences between shoot types were maintained, as the basal diameter of shoots increased steadily throughout the growing season. There was also a small but significant $(p<0.05)$ effect of rootstock on shoot basal diameter from January, with shoot diameters from vines on $A$. macrosperma rootstocks being slightly larger than those from vines on 'Bruno' rootstocks.

The diameter of the cane at the position that long shoots developed from was significantly $(p<0.001)$ larger $(14.4 \pm 0.2 \mathrm{~mm})$ than the position where small and medium shoots developed (12.1 \pm 0.2 and $12.2 \pm 0.2 \mathrm{~mm}$ respectively). However, as there was no difference in the basal diameter of canes that produced different shoot types $(16.5 \pm 0.4 \mathrm{~mm}$ for short shoots; $16.0 \pm 0.4 \mathrm{~mm}$ for medium shoots; $16.6 \pm 0.4 \mathrm{~mm}$ for long shoots), this suggests that long shoots developed at the proximal end of canes and small and medium shoots at more distal locations.

Although differences in the length of the different shoot types were apparent in October, these effects were only statistically significant from November when medium shoots $(p<0.05)$ were longer than short shoots and long shoots were $(p<0.001)$ longer than both medium and short shoots (Figure 3B). Short shoots did not increase in length after October, while medium shoots continued to grow until November and long shoots until January. There was no effect of rootstock type on shoot length. There was a significant $(p<0.001)$ effect of shoot type on average internode length from October (short $16.4 \pm 2.2 \mathrm{~mm}$, medium $34.3 \pm 2.7 \mathrm{~mm}$ and long $51.5 \pm 2.2 \mathrm{~mm}$ ) until the end of shoot growth, where average internode lengths on short shoots were $18.4 \pm 2.1 \mathrm{~mm}$, on medium shoots $45.5 \pm 2.2 \mathrm{~mm}$ and on long shoots $67.8 \pm 2.1 \mathrm{~mm}$. There was also a significant interaction $(p<0.001)$ between rootstock and shoot type whereby the average internode length of long shoots on 'Bruno' rootstocks was greater $(71.9 \pm 1.2 \mathrm{~mm})$ than those on long shoots from vines on A. macrosperma rootstocks $(64.2 \pm 1.3 \mathrm{~mm})$. 
The pattern of increasing leaf number followed that of shoot length, with the final number of leaves on short shoots being established in October, and on medium shoots by November, but leaf number continued to increase until January on long shoots (Figure 3C). Soon after anthesis, in November, the leaf number across all shoot types on vines with $A$. macrosperma rootstocks was significantly $(p<0.05)$ greater, by 1.5 leaves, than that of shoots from vines on 'Bruno' rootstocks and this difference was maintained for the remainder of the season (Figure 3C).

The effects of shoot type and rootstock on total shoot leaf area were also established early in the growing season (Figure 3D). Total leaf area development on short shoots was complete by October, while total leaf area continued to increase until November in medium shoots and until January in long shoots. In October, short shoots had significantly $(p<0.001)$ less total leaf area than long shoots (Figure 3D) and by November medium shoots also had significantly $(p<0.001)$ more total leaf area than short shoots but less than long shoots. In contrast to effects on leaf number, the total leaf area of fully developed long shoots from vines on 'Bruno' rootstocks was $0.451 \mathrm{~m}^{2}$ greater $(p<0.001)$ than long shoots from vines on $A$. macrosperma rootstocks, but there was no effect of rootstock on the total leaf area of short and medium shoots. These differences in leaf area were maintained over the rest of the season.
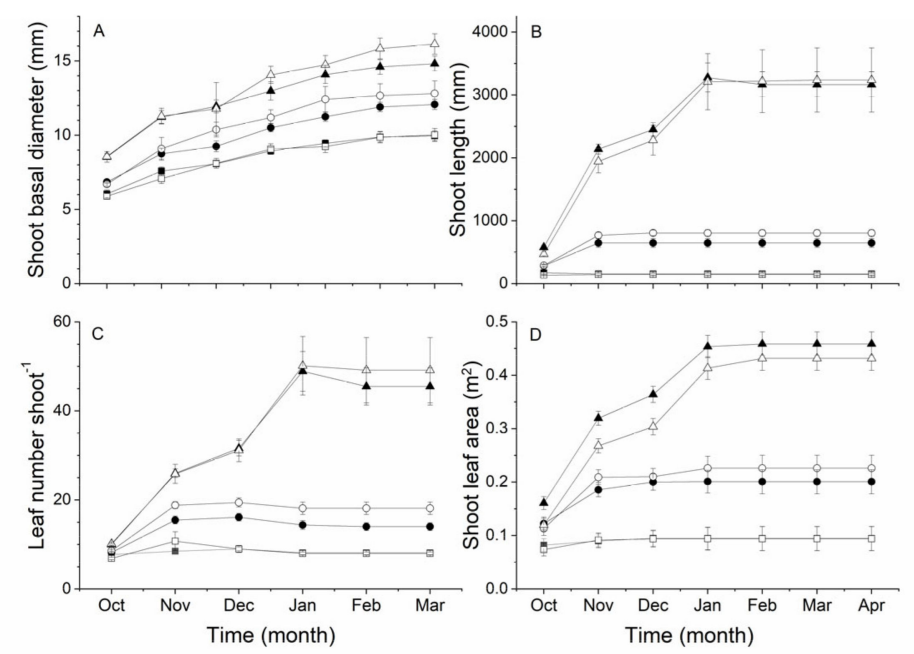

Figure 3. The effect of shoot type and rootstock on (A) shoot basal diameter, (B) shoot length, (C) leaf number per shoot and (D) total shoot leaf area of Actinidia chinensis var. chinensis 'Zes008' shoots over a growing season. Shoots were growing on vines on either A. chinensis var. deliciosa 'Bruno' rootstock (short $\boldsymbol{\square}$, medium $\bullet$ or long $\boldsymbol{\Delta}$ shoots) or an $A$. macrosperma rootstock (short $\square$, medium $\bigcirc$ or long $\triangle$ shoots). Data are means $\pm \mathrm{SEM}, n=8$.

\subsection{Growth of Individual Leaves along Shoots}

Throughout the growing season, the largest leaves in Zone 1 (leaves 1-9 on all shoot types) were found at nodes $4-6$, followed by nodes 7 and 3 , with the smallest leaves at positions 1, 2, 8 and 9 regardless of rootstock or shoot type (Figure 4). Leaf area was distributed curvilinearly in this zone of shoots. The significant effects of shoot type and rootstock on total shoot leaf area early in the growing season were due to differences in the area of individual leaves on the first nine nodes of the shoot (Zone 1 Figure 4 ). Leaves on short shoots had the smallest area $(p<0.01)$ across all leaves from October. Leaves on long shoots from vines on 'Bruno' rootstocks were the largest $(p<0.01)$, with leaves on other shoot type $\times$ rootstock combination falling between these extremes. 

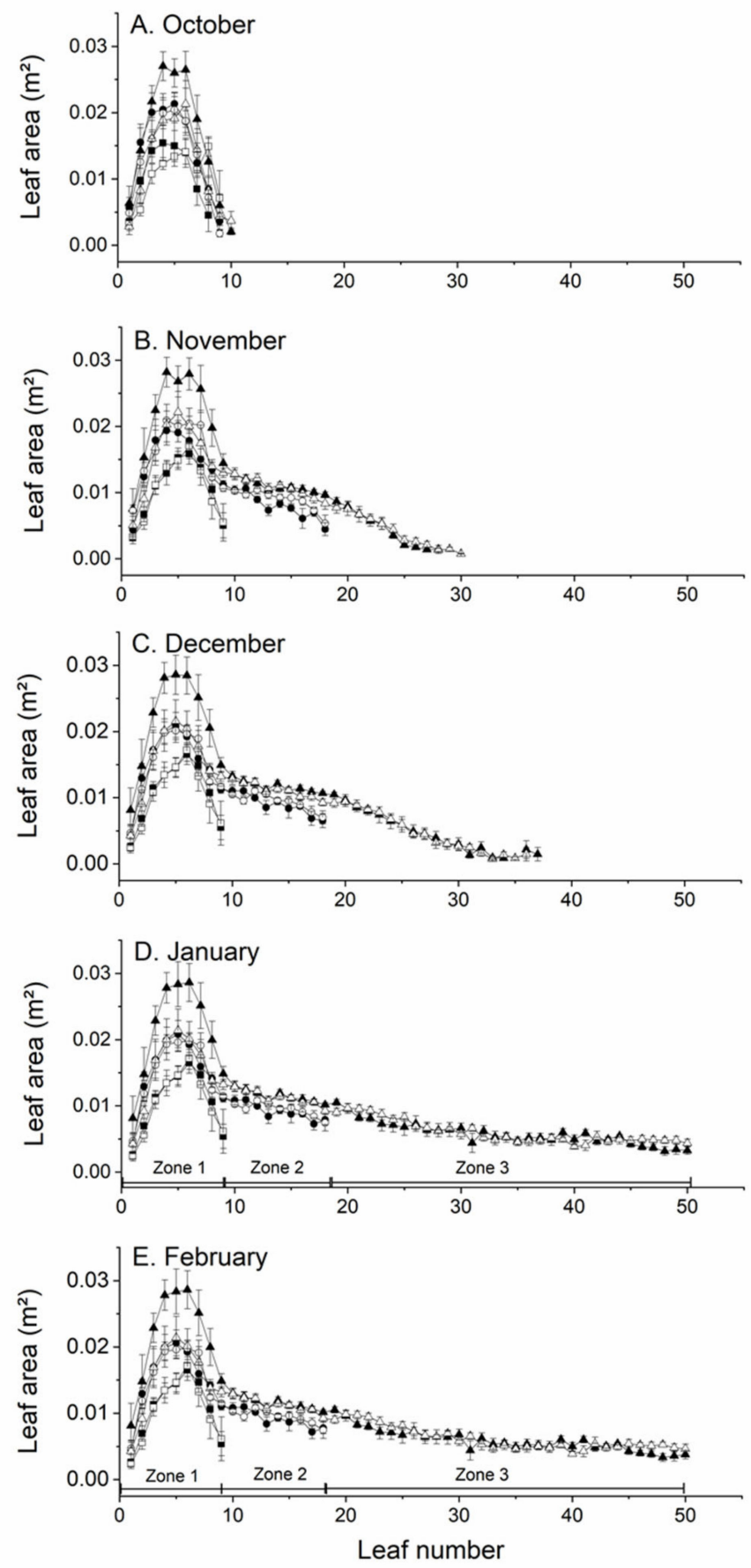

Figure 4. The effect of shoot type and rootstock on mean leaf area at different nodal positions along shoots Actinidia chinensis var. chinensis 'Zes008' in (A) October, (B) November, (C) December, (D) January, and (E) February during the growing season. Shoots were growing on vines with either A. chinensis var. deliciosa 'Bruno' rootstock (short $\mathbf{\square}$, medium $\bullet$ or long $\boldsymbol{\Delta}$ shoots) or an A. macrosperma rootstock (short $\square$, medium $\bigcirc$ or long $\triangle$ shoots). Leaves 1-9 were in Zone 1, leaves 10-18 were in Zone 2 and leaves 19 and greater were in Zone 3. Data are means \pm SEM, $n=8$. 
In Zone 2 (leaves 10-18 on medium and long shoots only), there was a significant $(p<0.05)$ linear decrease in leaf area with leaf position, with a $25 \%$ decrease in the area of leaves from leaf number 10 to leaf 18 (Zone 2 Figure 4). The average area of leaves in Zone 2 was greater on long shoots compared with those on medium shoots. In November the average size of leaves in Zone 2 of medium shoots was significantly $(p<0.05)$ greater for vines on $A$. macrosperma rootstocks compared with vines on 'Bruno' rootstocks but thereafter there were no significant effects of rootstock on leaf area in Zone 2.

In Zone 3 (leaves 19+ on long shoots only), there were eight leaves in November (total 26 leaves per shoot) and this increased to 30 by February (total 48 leaves per shoot). Individual leaf area decreased linearly throughout this zone, with a significant $(p<0.001)$ five-fold difference between the area of leaves at position 19 compared with those at the end of shoots (position 48) in February (Zone 3 Figure 4). There were no significant effects of rootstock on leaf area in this zone.

\subsection{Photosynthesis}

Soon after budbreak in October, there were significantly $(p<0.001)$ higher average photosynthetic rates across leaves on medium and long shoots compared with leaves on short shoots (Figure 5). There was also a significant effect $(p<0.001)$ of rootstock on the average photosynthetic rate of leaves in October, with average rates across shoots from vines on 'Bruno' rootstocks $\left(10.5 \pm 0.1 \mu \mathrm{mol} \mathrm{m} \mathrm{m}^{-2} \mathrm{~s}^{-1}\right)$ higher than across leaves on shoots from vines on $A$. macrosperma rootstocks $\left(9.30 \pm 0.40 \mu \mathrm{mol} \mathrm{m}^{-2} \mathrm{~s}^{-1}\right)$. These differences were due to effects on photosynthetic rates of leaves in Zone 1 of shoots (leaves at nodes 1-9) (Figure 6). In the following month (November) there were significant interactions between rootstock, shoot type and shoot zone on the average photosynthesis rate across leaves on shoots. Photosynthesis rates were significantly $\left(1.1 \mu \mathrm{mol} \mathrm{m} \mathrm{m}^{-2}\right)$ higher $(p<0.05)$ across leaves in Zone 1 of shoots from vines on $A$. macrosperma rootstocks (17.8 $\left.\pm 0.2 \mu \mathrm{mol} \mathrm{m} \mathrm{m}^{-2} \mathrm{~s}^{-1}\right)$ than in shoots from vines on 'Bruno' rootstock $\left(16.7 \pm 0.2 \mu \mathrm{mol} \mathrm{m} \mathrm{m}^{-2} \mathrm{~s}^{-1}\right)$, in contrast to the previous month. Short shoots also had significantly lower photosynthesis rates across leaves in Zone 1 than long shoots, while medium shoots had lower photosynthesis rates across leaves in Zone 2 compared to long shoots (Figure 6). By December, photosynthesis rates were higher across leaves on medium and long shoots from A. macrosperma rootstocks and across leaves on medium shoots from vines on 'Bruno' rootstocks than other rootstock $\times$ shoot type combinations (Figure 5). By this stage of shoot development, differences in average rates of photosynthesis were due to higher rates in leaves in both Zone 1 and also Zone 2 (leaves 10-18), where rates had exceeded those in Zone 1 (Figure 6). Thereafter (January-March), average photosynthesis rates were significantly lower $(p<0.001)$ in leaves on short shoots compared with those across leaves on medium and long shoots, regardless of rootstock type (Figure 5). This effect was due to both lower photosynthesis rates in leaves in Zone 1 of short compared to medium and long shoots and also higher photosynthesis rates of leaves in Zone 2 and 3 of medium and long shoots (Figure 6). The decline in average photosynthesis rates from December to January occurred as measurements were performed after vines were girdled. 


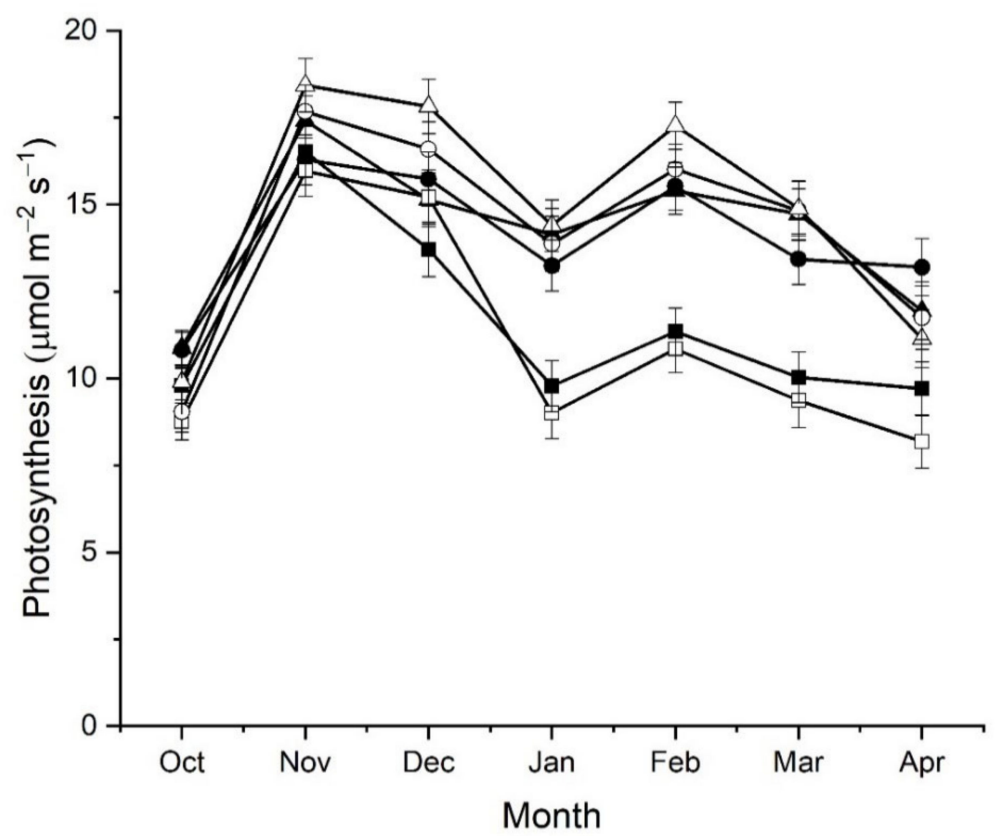

Figure 5. The effect of shoot type and rootstock on average net photosynthesis rates of leaves on Actinidia chinensis var. chinensis 'Zes008' shoots over a growing season. Measurements were taken from every second leaf sampled along individual shoots, to calculate an average value per shoot. Shoots were growing on vines with either A. chinensis var. deliciosa 'Bruno' rootstock (short $\mathbf{\square}$ medium $\bullet$ or long $\Delta$ shoots) or an $A$. macrosperma rootstock (short $\square$, medium $\bigcirc$ or long $\triangle$ shoots). Data are means of measurements from individual shoots $\pm \mathrm{SEM}, n=8$.
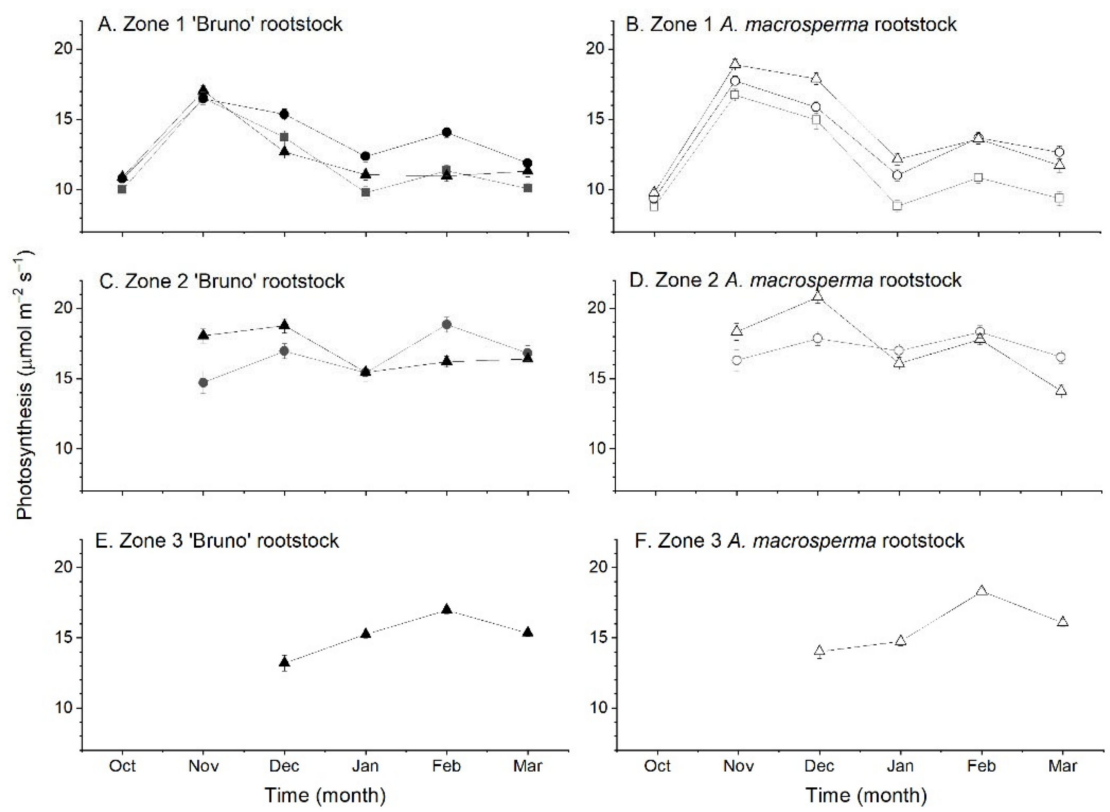

Figure 6. The effect of shoot type and rootstock on the net photosynthesis rate with leaf zone position on shoots of Actinidia chinensis var. chinensis 'Zes008' over a growing season (A) A. chinensis var. deliciosa 'Bruno' rootstock Zone 1-leaves 1-9 (B) A. macrosperma rootstock Zone 1, (C) A. chinensis var. deliciosa 'Bruno' rootstock Zone 2-leaves 10-18, (D) A. macrosperma rootstock Zone 2, (E) A. chinensis var. deliciosa 'Bruno' rootstock Zone 3-leaves 19 and greater and (F) A. macrosperma rootstock Zone 3. Shoot types are identified by A. chinensis var. deliciosa 'Bruno' rootstock (short $\mathbf{\square}$, medium $\bullet$ or long $\mathbf{\Delta}$ shoots) or an $A$. macrosperma rootstock (short $\square$, medium $\bigcirc$ or long $\triangle$ shoots). Data are means across each zone and shot type $\times$ rootstock combination \pm SEM, $n=8$. 


\subsection{Fruit Development}

Data on fruit growth, dry matter accumulation and maturation (SSC and firmness) were normalised against maximum values (Figure 7A). Initially fruit growth was slow but fruit weight increased rapidly from 28 DAA to 112 DAA and then slowed again as fruit matured (Figure 7A). The dry matter of ovaries was $12 \%$ at anthesis, decreased to a minimum $(8.7 \%)$ in fruit at 42 DAA and then increased steadily from 56 DAA until harvest (189 DAA) when fruit dry matter reached $23.8 \%$ (Figure 7A). From 105 DAA, the SSC increased steadily to $19.5 \%$ and fruit firmness decreased reaching $3.7 \mathrm{kgf}$ at the end of fruit development. No red pigmentation was present in the ovaries or fruitlets during early fruit development (Figure 7B). Red pigmentation appeared in both the inner and outer pericarp tissues, starting at 84 DAA and intensifying over the remainder of fruit development.
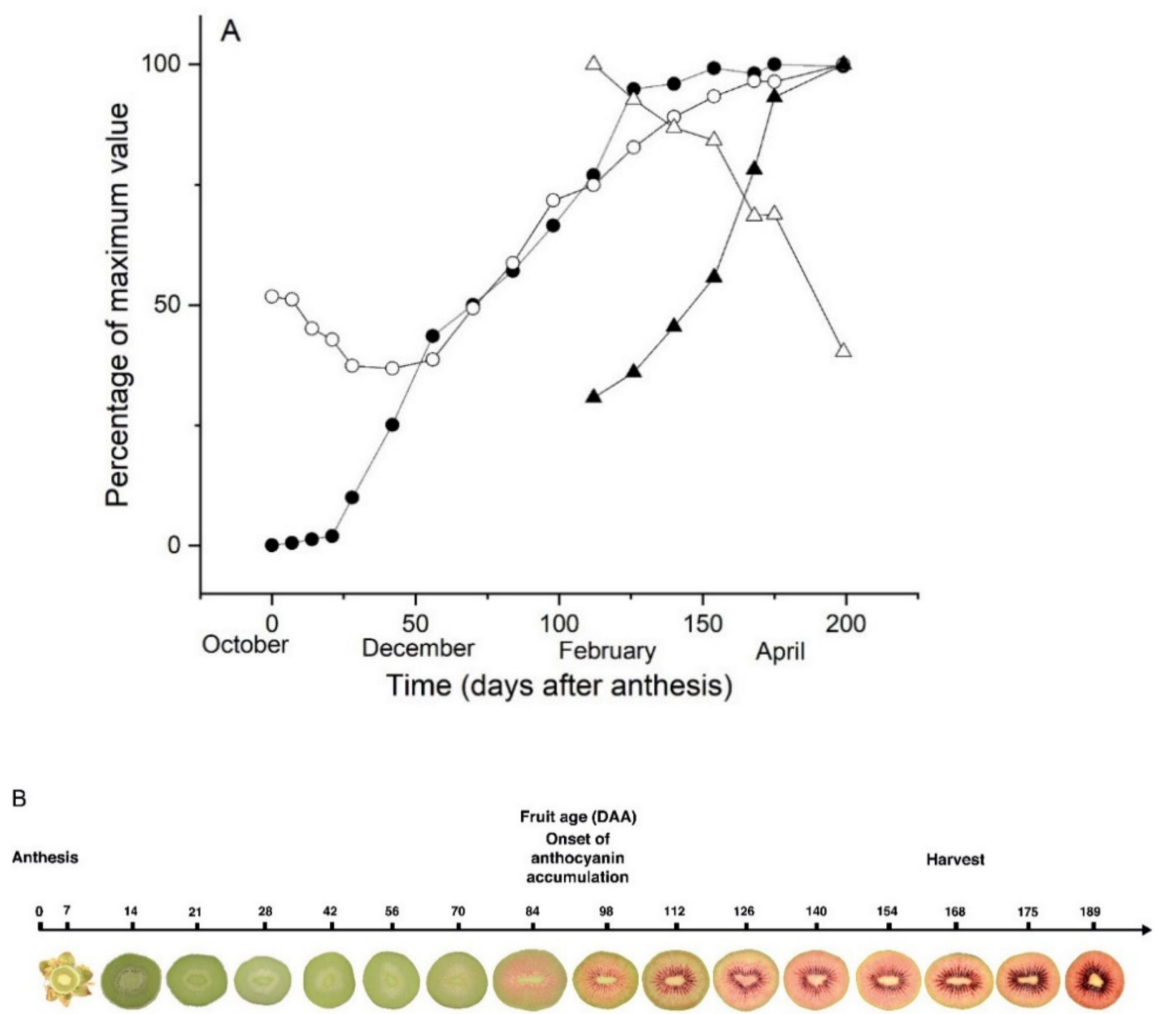

Figure 7. Development of Actinidia chinensis var. chinensis 'Zes008' fruit from anthesis until maturity. (A) Physiological changes in fruit were normalised as a percentage of the maximum value for fruit fresh weight $\bullet$, fruit dry matter $\bigcirc$, soluble solids concentration $\boldsymbol{\Lambda}$, and fruit firmness $\triangle$ over the growing season. Data are means $\pm \mathrm{SEM}, n=15$. (B) Cross sections of typical fruit throughout development (not to scale).

\subsection{The Effect of Shoot Type and Rootstock on Fruit Weight, Dry Matter, Maturity and} Pigmentation of the Outer Pericarp at Harvest

There was a significant $(p<0.05)$ interaction between rootstock and shoot type on the final weight of fruit. Fruit from medium shoots were significantly larger than those from short shoots from vines on 'Bruno' rootstocks $(\mathrm{LSD}=3.16)$. On vines on A. macrosperma rootstocks, medium shoots produced significantly $(p<0.05)$ larger fruit than short or long shoots. Short shoots produced fruit with significantly $(p<0.001)$ lower dry matter and SSC than fruit from medium and long shoots (Table 1) regardless of vine rootstock. Fruit from medium shoots were more mature at harvest, having higher SSC and lower firmness values than fruit from long shoots. There was a significant $(p<0.001)$ effect of rootstock on fruit quality with fruit from vines on 'Bruno' rootstocks having higher fruit dry matter, 
SSC and firmness at harvest compared with fruit from vines on A. macrosperma rootstocks (Table 1).

Fruit from long shoots had fewer carpels than fruit from medium and short shoots and were significantly $(p<0.05)$ more cylindrical (similar equatorial diameters) regardless of vine rootstock. However, fruit from vines on $A$. macrosperma rootstocks produced fruit with significantly $(p<0.001)$ more carpels than fruit from vines on 'Bruno' rootstocks.

Table 1. The effect of rootstock (Actinidia chinensis var. deliciosa 'Bruno' or A. macrosperma clonal rootstock) and shoot type (short, medium or long) on A. chinensis var. chinensis 'Zes008' fresh fruit weight, fruit dry matter, soluble solids content (SSC), firmness (kilogram force (kgf), carpel number and minimum/maximum diameter ratio at harvest (168 DAA). Data are means $\pm \mathrm{SEM}, n=50$. ${ }^{*} p<0.05 ;{ }^{* * *} p<0.001$; ns: not significant.

\begin{tabular}{|c|c|c|c|c|c|c|c|}
\hline Rootstock & Shoot Type & $\begin{array}{c}\text { Fresh } \\
\text { Weight (g) }\end{array}$ & $\begin{array}{l}\text { Dry Matter } \\
(\%)\end{array}$ & SSC (\%) & $\begin{array}{l}\text { Firmness } \\
\text { (kgf) }\end{array}$ & $\begin{array}{l}\text { Carpel } \\
\text { Number }\end{array}$ & $\begin{array}{l}\text { Minimum/Maximum } \\
\text { Diameter Ratio }\end{array}$ \\
\hline $\begin{array}{c}\text { A. chinensis } \\
\text { var. deliciosa } \\
\text { 'Bruno' }\end{array}$ & Short & $81.8 \pm 1.1$ & $20.0 \pm 0.1$ & $10.9 \pm 0.2$ & $6.19 \pm 0.08$ & $32.3 \pm 0.3$ & $0.864 \pm 0.007$ \\
\hline $\begin{array}{l}\text { A. chinensis } \\
\text { var. deliciosa } \\
\text { 'Bruno' }\end{array}$ & Medium & $85.6 \pm 1.1$ & $20.2 \pm 0.1$ & $11.8 \pm 0.2$ & $6.12 \pm 0.08$ & $32.5 \pm 0.3$ & $0.867 \pm 0.007$ \\
\hline $\begin{array}{l}\text { A. chinensis } \\
\text { var. deliciosa } \\
\text { 'Bruno' }\end{array}$ & Long & $83.2 \pm 1.2$ & $20.5 \pm 0.1$ & $11.4 \pm 0.2$ & $6.49 \pm 0.08$ & $32.2 \pm 0.3$ & $0.878 \pm 0.007$ \\
\hline $\begin{array}{c}A . \\
\text { macrosperma } \\
\text { rootstock }\end{array}$ & Short & $79.8 \pm 1.1$ & $18.7 \pm 0.1$ & $9.4 \pm 0.2$ & $5.71 \pm 0.08$ & $34.2 \pm 0.3$ & $0.853 \pm 0.007$ \\
\hline $\begin{array}{c}A . \\
\text { macrosperma } \\
\text { rootstock }\end{array}$ & Medium & $83.6 \pm 1.1$ & $19.1 \pm 0.1$ & $10.1 \pm 0.2$ & $5.88 \pm 0.08$ & $33.6 \pm 0.3$ & $0.857 \pm 0.007$ \\
\hline $\begin{array}{c}A . \\
\text { macrosperma } \\
\text { rootstock }\end{array}$ & Long & $76.0 \pm 1.1$ & $18.9 \pm 0.1$ & $9.5 \pm 0.2$ & $6.03 \pm 0.08$ & $32.9 \pm 0.3$ & $0.872 \pm 0.007$ \\
\hline
\end{tabular}

\begin{tabular}{|c|c|c|c|c|c|c|}
\hline \multicolumn{7}{|c|}{ Significance } \\
\hline Rootstock & $* * *$ & $* * *$ & $* * *$ & $* * *$ & $* * *$ & ns \\
\hline Shoot type & $* * *$ & $* * *$ & $* * *$ & $* * *$ & * & * \\
\hline Rootstock*Shoot & * & ns & ns & ns & ns & ns \\
\hline
\end{tabular}

Shoot type had an effect on the red pigment intensity and spread in the fruit regardless of the vine rootstock (Table 2). Fruit from short shoots consistently had significantly $(p<0.001)$ less red pigmentation in the fruit outer pericarp and less spread of red pigmentation throughout the fruit flesh compared to fruit from other shoot types. However, fruit from short shoots also had a slightly higher red score in the inner pericarp than fruit from other shoot types.

The data presented suggest that shoot characteristics early in the growing season affect the final fruit quality at harvest. To verify this we have used the sparse partial least Squares (sPLS) technique to look at the correlation-based relationship between shoot variables ( $\mathrm{X}$, with data collected in November) and fruit variables $(\mathrm{Y}$, with data collected at harvest), maximising the covariance between components from two data sets using linear combinations of variables. The seven $X$ and the seven $Y$ variables are listed in Table S1 with the respective loading vectors for each component. Results from the sPLS analysis were presented by correlation circle plots (Figure 8A). In this type of plot, relationships are stronger when variables are further from the origin, fall outside the inner circle, and less than 90 degrees away from each other. On this basis, we observed a correlation between 
five shoot variables (shoot diameter, shoot length, number of leaves, internode length and leaf area) and two fruit variables (flesh red spread and red intensity outer pericarp). The variables fruit weight and mean photosynthesis did not correlate with the cluster of five shoot variables. The variables within the inner circle were not correlated with other variables. The sPLS xy-bivariate plot generated using the loading of the shoot and fruit variables (Figure 8B) showed a separation of the three shoot types on the XY-variate 1, where long shoots mostly cluster on the left hand side of the plot, short shoots cluster on the right hand side and medium shoots are in the middle but there was no effect of vine rootstock type on this relationship.

Table 2. The effect of shoot type (short, medium or long) of red-fleshed Actinidia chinensis var. chinensis 'Zes008' fruit red pigment scores in the inner pericarp and outer pericarp of fruit, and the spread of red pigment through the fruit tissues at harvest (168 DAA). Flesh colour was measured using a scale of 0 to $5(0=$ absent; $5=$ very intense red $)$ and the spread of red pigment throughout the fruit pericarp tissues was also scored on a 0 to 5 scale $(0=$ no red pigmentation; $5=$ red pigmentation spread throughout the pericarp). Data are means \pm SEM, $n=50 .{ }^{*} p<0.05 ;{ }^{* * *} p<0.001$.

\begin{tabular}{cccc}
\hline Shoot Type & $\begin{array}{c}\text { Inner Pericarp Red } \\
\text { Pigment Score }\end{array}$ & $\begin{array}{c}\text { Outer Pericarp Red } \\
\text { Pigment Score }\end{array}$ & Red Pigment Spread \\
\hline Short & $4.98 \pm 0.02$ & $3.14 \pm 0.06$ & $4.67 \pm 0.03$ \\
\hline Medium & $4.93 \pm 0.02$ & $3.55 \pm 0.06$ & $4.81 \pm 0.03$ \\
\hline Long & $4.92 \pm 0.02$ & $3.63 \pm 0.06$ & $4.92 \pm 0.03$ \\
\hline Significance & $*$ & $* * *$ & $* *$ \\
\hline
\end{tabular}
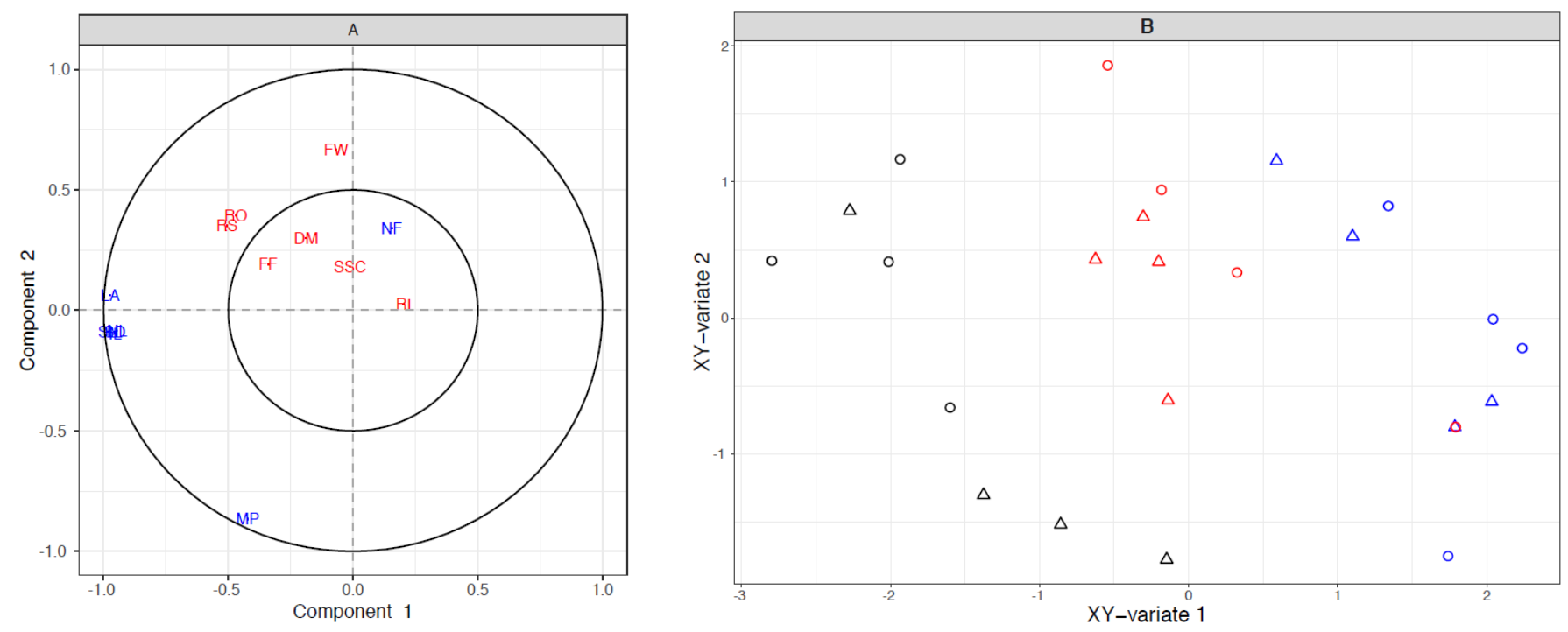

Figure 8. Correlation based relationships between shoot variables ( $X$, with data collected in November) and fruit variables (Y, with data collected at harvest) for Actinidia chinensis var. chinensis 'Zes008' vines. (A) Correlation circle plots of $\mathrm{X}$ (blue-shoot) variables (SD, shoot diameter, SL, shoot length, NF, number of fruit, NL, number of leaves, IL, internode length, LA, leaf area, MP, mean photosynthesis) with Y (red-fruit) variables (FW, fresh weight, DM, dry matter, FF, firmness, SSC, soluble solids content, RS, red pigment spread, RI, inner pericarp red pigment, RO, outer pericarp red pigment). Cluster of blue-shoot variables at position $(-1.0,-0.1)$ includes: SD, SL, NL and IL. (B) sPLS xy-bivariate plot using shoot and fruit variables. Symbol colour represents shoot type (blue-short shoots, red-medium shoots, black-long shoots) while $\bigcirc$ represent shoots from vines with 'Bruno' rootstocks and $\triangle$ represents shoots from vines on $A$. macrosperma rootstocks.

\section{Discussion}

Kiwifruit canopies are composed of a population of short, medium and long shoots and the number and performance of these shoots can be influenced by rootstock and scion 
genetics as well as vine management. This study demonstrated that during the very early stages of bud development shoot type and rootstock determined the ability of leaves to photosynthesise and supply carbohydrate to support fruit development throughout the remainder of the season on red-fleshed A. chinensis var. chinensis 'Zes008' vines. During the very early stages of rapid canopy and flower development on 'Zes008' vines, leaves on short shoots were smaller and had lower photosynthesis rates than those on medium and long shoots. These differences in the ability of shoot types to acquire carbon through photosynthesis increased throughout the growing season as more leaves developed on medium and long shoots. Rootstock type also altered the development of shoots, resulting in smaller but significant differences in carbon acquisition from photosynthesis. Differences in shoot properties were associated with variation in the size, dry matter, maturity of 'Zes008' fruit at harvest and early shoot properties were associated with red pigmentation of 'Zes008' fruit at harvest.

\subsection{Shoot and Rootstock Type Affect Early Shoot and Leaf Growth}

In 'Zes008' vines, short shoots typically produced nine leaves and their growth terminated in October, medium shoots produced 18 leaves and their growth terminated in November and long shoots produced approximately 50 leaves and shoots continued to grow until January, regardless of rootstock type. We observed that average shoot internode length increased from short to long shoot types, suggesting that long shoots expanded faster than short shoots. Once kiwifruit shoots stop expanding, shoot tip abortion occurs and shoot growth is terminated [40]. The timing of the slowing of shoot expansion and shoot tip termination determines the shoot type category (short, medium or long) [41].

Differences in the characteristics of short, medium and long shoot types of 'Zes008' were evident from October (three weeks after budbreak) and continued to diverge throughout the rest of the season. The diameter, length and leaf area of the three shoot types differed as the initial leaf cluster opened and expansion of the first preformed leaves and the shoot axis occurred, in agreement with results from Brundell [35]. Early differences in shoot length were due to variation in the extension of internodes rather than a difference in node number between shoot types. The difference in internode length, measured at the end of the shoot growth, has been used to define shoot types for Actinidia spp. [41] and also been noted in previous studies of $A$. chinensis var. deliciosa 'Hayward' kiwifruit [56] and in 'Semillon' grapevine shoots [39].

Leaf area development on shoots followed a similar pattern to internode and shoot extension. In short shoots leaf area development was completed by October, in medium shoots by November, but it continued to increase until January in long shoots. Previous studies of long 'Hayward' kiwifruit shoots have shown a close relationship between shoot extension and leaf area development when vines were grown in controlled environments $[28,57]$. In the current study, shoots that developed on vines on 'Bruno' rootstocks also had greater leaf area than those that developed on A. macrosperma rootstocks, regardless of shoot type. A previous study of 'Hort16A' kiwifruit scions on a range of rootstocks showed that the leaf area of terminated shoots (short and medium shoots) was reduced on vines with lower vigour rootstocks [58].

Differences in the total leaf area of each shoot type were due to differences in the area of individual leaves on each shoot type rather than the number of leaves. Leaves of 'Zes008' shoots developed differently in the three zones and this is similar to a previous study of 'Hayward' kiwifruit vines [42]. The area of each of the first nine leaves in Zone 1 followed a curvilinear distribution along each shoot, regardless of shoot type. There was a rapid increase in leaf area from the base of the shoot, peaking at node 4-6 and then declining rapidly to node 10 . Thereafter, there was a steady linear decline in leaf area with increasing node number up to c. 50 nodes. This differs from previous studies of the highly vigorous and less floral 'Hayward' [59] and 'Hort16A' [43] kiwifruit shoots, where leaf area increased to a peak at node 10 and then gradually decreased with increasing node number. This suggests that for 'Zes008', which is less vigorous and highly floral, the 
demand for carbohydrate becomes critical very soon after budbreak, and this impacts on early development of all shoot components, including leaves, flowers and the shoot apex. The size of the largest early developing leaves in Zone 1 was greater on long shoots of vines on 'Bruno' rootstocks than other rootstock $\times$ shoot type combinations, suggesting that early supply of carbohydrate to shoots is a key factor, as previously observed in 'Hort16A' kiwifruit [43]. In that study it was suggested that rootstock vigour affected the supply of carbohydrate to developing leaves on long shoots of 'Hort16A'.

\subsection{Source Strength Varies between Shoot and Rootstock Types from Soon after Budbreak}

Average photosynthetic rates of leaves increased rapidly during their early development, with maximum photosynthetic rates occurring once leaves had expanded fully. This is in agreement with previous results with 'Hayward' kiwifruit [56,59] and 'Sultana' grapevines [60]. Maximum photosynthesis rates of $20.8 \mu \mathrm{mol} \mathrm{m} \mathrm{m}^{-2} \mathrm{~s}^{-1}$ recorded in the current study were similar to maximum rates of up to $20.1 \mu \mathrm{mol} \mathrm{m} \mathrm{m}^{-2} \mathrm{~s}^{-1}$ measured on leaves of several Actinidia species [61] but higher than maximums of $12-15 \mu \mathrm{mol} \mathrm{m}^{-2} \mathrm{~s}^{-1}$ recorded in previous studies of $A$. chinensis var. deliciosa cultivars [62,63]. The peak of photosynthesis was followed by a gradual decline in average photosynthetic rates over time, as previously reported in a range of Actinidia species [61-63] and grapevines [60,64]. However, the dip in photosynthesis rates in January occurred after the second girdle was applied to vines, a response to trunk girdling previously observed by Black et al. [65]. Petrie, Trought and Howell [64] suggested that this seasonal decline in average photosynthetic rates in Pinot noir grapevine leaves was due to the overall change in the source-sink ratio of the plant as the canopy developed.

The effects of shoot and rootstock types on both shoot growth and leaf area development were reflected in significant differences in the photosynthetic rates of early developing leaves. Differences in the average photosynthetic rates of Zone 1 between shoot types occurred soon after budbreak. Whilst a modelling study on peach suggested that differences between photosynthetic rates of shoots was due to shading [66], this was not the case in the current study as there were no effects of shading between shoots soon after budbreak and thereafter shoots were maintained in well-lit positions within the canopy throughout the season. We suggest that these early differences in photosynthetic rates between shoot types, which have not been previously reported for Actinidia spp., were due to factors such as source-sink ratios within shoots [67], transpiration rates [57] or other biochemical and structural properties of leaves [68].

There were variable effects of rootstocks on the photosynthetic rates of leaves during the early stages of development. Leaves on shoots from vines on 'Bruno' rootstocks had higher average photosynthetic rates in October than those from vines on A. macrosperma rootstocks, although this was reversed in the following months. This, together with leaf area development, suggests that rootstock type may have affected the timing of leaf development. Previous work has indicated that, in kiwifruit, root systems can affect canopy photosynthetic performance via stomatal and biochemical processes in leaves [69,70], and that rootstock type can affect the rate of canopy development and vigour in spring [71].

Early slowing of shoot growth in short and medium shoots shown in this study has previously been related to reduced carbohydrate supply from vine reserves [38] or to competition for carbohydrate between neighbouring shoots [43]. The relationship between shoot type and the cane diameter at the base of the shoot found in this and previous studies $[41,72,73]$ suggests that long shoots were more likely to develop at the proximal end of the canes, where access to stored carbohydrate reserves was likely greater, while short and medium shoots were distributed along the more distal portions of canes. Early breaking buds are the first to access vine reserves and also tend to produce longer shoots, while short shoots develop from later breaking buds (Richardson unpublished data). The termination of medium shoots was likely due to a combination of lower reserve supply to shoots and lower production of photosynthate by leaves during the transition of the shoot from heterotrophy to autotrophy [28,56,57]. Modifying photosynthate production in 
developing shoots through early defoliation [56] or shading [12,74] during spring has also been shown to reduce shoot growth.

\subsection{Variation in Source Carbohydrate Supply Affects Fruit Quality at Harvest}

Carbohydrate supply from leaves associated with the fruit supports fruit growth and metabolite accumulation in the red-fleshed 'Zes008' kiwifruit. Fruit that developed on more vigorous shoots (medium and long) and on vines on 'Bruno' rootstocks had the highest dry matter and highest SSC at harvest, as previously observed in another red-fleshed kiwifruit [17]. Results from the current study have suggested that early carbohydrate supply from reserves to shoots affects both leaf area development and photosynthesis rates of leaves in Zone 1. In kiwifruit, spring (October) is also a key period of flower differentiation [75]. A previous study of gold-fleshed 'Zesy002' kiwifruit has shown that size, dry matter and amount of outer pericarp tissue in fruit at harvest was related to time of flowering, suggesting that competition for carbohydrate during flower development has an important influence on kiwifruit development and quality [19].

This study suggests that there is a relationship between early shoot development (November, Zone 2 leaves expand) and fruit characteristics at harvest. Fruit from medium and long shoots also had more intense outer pericarp red pigmentation than fruit from short shoots and there was a high correlation between shoot properties and fruit red pigmentation. The higher photosynthetic capacity of leaves of medium and long shoots contributed to a greater carbohydrate supply to fruit throughout their development. This is in agreement with our earlier studies that leaf carbohydrate supply is important for intensity of fruit outer pericarp red pigmentation [17,31]. From the current study, we conclude that the carbohydrate supply to shoots in spring during the very early stages of their development affects the capacity of leaves to supply carbohydrate to fruit throughout the season, as well as the ability of fruit sinks to accumulate carbohydrate, thereby influencing variability in fruit dry matter and fruit outer pericarp red pigmentation at harvest. Future research should focus on understanding the impact of phytohormones balance (i.e., cytokinin and auxin) on shoot carbohydrate concentration and photosynthetic performance during early fruit development in different shoot types.

\section{Conclusions}

The results from this study suggest that carbohydrate supply during the very early stages of shoot development affected the subsequent performance of leaves and fruit throughout the remainder of the season. The number, size and photosynthetic capacity of leaves varied across shoot types, affecting their ability to supply carbohydrate to the associated flowers/fruit throughout their development. This difference in carbohydrate supply was manifested in the variability in size, dry matter and outer pericarp red pigmentation in fruit at harvest. Rootstock type also influenced the capacity of shoots to supply carbohydrate to fruit during their development and hence fruit quality at harvest. Further research is needed to examine the factors that influence the very early development of kiwifruit buds and the resulting leaves and flowers.

Supplementary Materials: The following are available online at https: / www.mdpi.com/2073-4 395/11/1/66/s1, Table S1: The loading vectors of seven shoot variables and fruit variables to each component used in SPLS analysis.

Author Contributions: Conceptualisation A.R. and S.N.; methodology A.R., H.J. and S.N.; investigation V.E., P.K. and D.E.; data curation V.E., formal analysis A.R., V.E., H.J. and S.N, writing original draft, review and editing A.R. and S.N.; funding acquisition S.N. and A.R. All authors have read and agreed to the published version of the manuscript.

Institutional Review Board Statement: Not applicable.

Informed Consent Statement: Not applicable. 
Data Availability Statement: The data presented in this study are available on request from the corresponding author (A.R.). The data are not publicly available due to privacy reasons.

Funding: This work was part of The New Zealand Institute for Plant and Food Research Limited Future Orchard Production Systems (Contract No. 30512) and the Premium Kiwifruit SSIF programmes funded through the New Zealand Ministry of Business, Innovation and Employment Science Investment Fund and a project funded by Zespri Group Limited.

Conflicts of Interest: The authors declare no conflict of interest.

\section{References}

1. Daniels, M.; Simonne, A.H.; Jensen, S.; Diehl, D.; Shelnutt, K.P.; Bruhn, C.; Brecht, J.K.; Wysocki, A.F.; Cook, R.; Mitcham, E. Consumer perceptions of quality and price of high-value specialty crops in supermarkets in the United States: Lessons for producers, handlers and educators. In III Asia Pacific Symposium on Postharvest Research, Education and Extension: Aps2014; Roberts, R.E., LayYee, M., Nguyen, D.D., Eds.; International Society for Horticultural Science Acta Horticulturae: Leuven, Belgium, 2018; Volume 1213, pp. 21-30.

2. Finlayson, C. Perfect food: Perspectives on consumer perceptions of fresh produce quality. Fennia 2018, 196, 168-186. [CrossRef]

3. Gamble, J.; Jaeger, S.R.; Harker, F.R. Preferences in pear appearance and response to novelty among Australian and New Zealand consumers. Postharvest Biol. Technol. 2006, 41, 38-47. [CrossRef]

4. Harker, F.R.; Gunson, F.A.; Jaeger, S.R. The case for fruit quality: An interpretive review of consumer attitudes, and preferences for apples. Postharvest Biol. Technol. 2003, 28, 333-347. [CrossRef]

5. Jaeger, S.R.; MacFie, H.J.H. The effect of advertising format and means-end information on consumer expectations for apples. Food Qual. Prefer. 2001, 12, 189-205. [CrossRef]

6. Musacchi, S.; Serra, S. Apple fruit quality: Overview on pre-harvest factors. Sci. Hortic. 2018, 234, 409-430. [CrossRef]

7. Deliza, R.; MacFie, H.J.H. The generation of sensory expectation by external cues and its effect on sensory perception and hedonic ratings: A review. J. Sens. Stud. 1996, 11, 103-128. [CrossRef]

8. Kummu, M.; de Moel, H.; Porkka, M.; Siebert, S.; Varis, O.; Ward, P.J. Lost food, wasted resources: Global food supply chain losses and their impacts on freshwater, cropland, and fertiliser use. Sci. Total Environ. 2012, 438, 477-489. [CrossRef]

9. Tombesi, A.; Antognozzi, E.; Palliotti, A. Influence of light exposure on characteristics and storage life of kiwifruit. N. Z. J. Crop Hortic. Sci. 1993, 21, 85-90. [CrossRef]

10. Palmer, J.; Diack, R.; Johnston, J.; Boldingh, H. Manipulation of fruit dry matter accumulation and fruit size in 'Scifresh' apple through alteration of the carbon supply, and its relationship with apoplastic sugar composition. J. Hortic. Sci. Biotech. 2013, 88, 483-489. [CrossRef]

11. Richardson, A.C.; Marsh, K.B.; Boldingh, H.L.; Pickering, A.H.; Bulley, S.M.; Frearson, N.J.; Ferguson, A.R.; Thornber, S.E.; Bolitho, K.M.; Macrae, E.A. High growing temperatures reduce fruit carbohydrate and vitamin C in kiwifruit. Plant Cell Environ. 2004, 27, 423-435. [CrossRef]

12. Greer, D.H.; Weston, C. Heat stress affects flowering, berry growth, sugar accumulation and photosynthesis of Vitis vinifera cv. Semillon grapevines grown in a controlled environment. Funct. Plant Biol. 2010, 37, 206-214. [CrossRef]

13. Nardozza, S.; Boldingh, H.L.; Richardson, A.C.; Costa, G.; Marsh, H.; MacRae, E.A.; Clearwater, M.J. Variation in carbon content and size in developing fruit of Actinidia deliciosa genotypes. Func. Plant Biol. 2010, 37, 545-554. [CrossRef]

14. Desnoues, E.; Gibon, Y.; Baldazzi, V.; Signoret, V.; Genard, M.; Quilot-Turion, B. Profiling sugar metabolism during fruit development in a peach progeny with different fructose-to-glucose ratios. BMC Plant Biol. 2014, 14, 336. [CrossRef] [PubMed]

15. Currie, M.B.; Patterson, K.J.; Snelgar, W.P.; Blattmann, P. Girdling kiwifruit vines for commercial advantage: Opportunities and risks. In IX International Symposium on Kiwifruit 1218; Antunes, M.D., Gallego, P.P., Eds.; International Society for Horticultural Science Acta Horticulturae: Leuven, Belgium, 2018; pp. 405-412.

16. Thorp, T.G.; Barnett, A.M.; Blattmann, M.; Hedderley, D.; Mayston, R. Optimising vine management to increase yields and improve quality of Zespri SunGold kiwifruit (Actinidia chinensis var. chinensis 'Zesy002'). In IX International Symposium on Kiwifruit 1218; Antunes, M.D., Gallego, P.P., Eds.; International Society for Horticultural Science Acta Horticulturae: Leuven, Belgium, 2018; pp. 397-404.

17. Nardozza, S.; Kashuba, P.; McCaughan, L.; Philippe, M.; Wohlers, M.; Montefiori, M.; Currie, M.; Richardson, A. Leaves are important to obtain consistent red flesh pigmentation in Actinidia chinensis fruit. Sci. Hortic. 2015, 197, 496-503. [CrossRef]

18. Trought, M.C.T.; Naylor, A.P.; Frampton, C. Effect of row orientation, trellis type, shoot and bunch position on the variability of Sauvignon Blanc (Vitis vinifera L.) juice composition. Aust. J. Grape Wine Res. 2017, 23, 240-250. [CrossRef]

19. Richardson, A.; Boldingh, H.; Kashuba, P.; Knight, G.; Ellingham, D. Flowering time determines the weight and composition of Actinidia chinensis var. chinensis 'Zesy002' kiwifruit. Sci. Hortic. 2019, 246, 741-748. [CrossRef]

20. Osorio, S.; Ruan, Y.L.; Fernie, A.R. An update on source-to-sink carbon partitioning in tomato. Front. Plant Sci. $2014,5,516$. [CrossRef]

21. Lai, R.; Woolley, D.J.; Lawes, G.S. Patterns of assimilate transport from leaves to fruit within a kiwifruit (Actinidia deliciosa) Lateral. J. Hortic. Sci. 1988, 63, 725-730. [CrossRef] 
22. Bertin, N. Competition for assimilates and fruit position affect fruit-set in indeterminate greenhouse tomato. Ann. Bot. 1995, 75, 55-65. [CrossRef]

23. Pyke, N.B.; Hopkirk, G.; Alspach, P.A.; Cooper, K.M. Variation in harvest and storage quality of fruit from different positions on kiwifruit vines. N. Z. J. Crop Hortic. Sci. 1996, 24, 39-46. [CrossRef]

24. Landi, M.; Tardelli, F.; Remorini, D.; Massai, R.; Guidi, L. Do sun- versus shade-grown kiwifruits perform differently upon storage? An overview of fruit maturity and nutraceutical properties of whole and fresh-cut produce. J. Agric. Food. Chem. 2014, 62, 4377-4383. [CrossRef]

25. Henwood, R.J.T.; Wargent, J.J.; Black, M.; Heyes, J.A. Environmental and management factors contributing to variability in flesh colour of a red kiwifruit cultivar in New Zealand. Sci. Hortic. 2018, 235, 21-31. [CrossRef]

26. Lai, R.; Woolley, D.J.; Lawes, G.S. The effect of inter-fruit competition, type of fruiting lateral and time of anthesis on the fruit-growth of kiwifruit (Actinidia deliciosa). J. Hortic. Sci. 1990, 65, 87-96. [CrossRef]

27. Inglese, P.; Caruso, T.; Gugliuzza, G.; Pace, L.S. Crop load and rootstock influence on dry matter partitioning in trees of early and late ripening peach cultivars. J. Am. Soc. Hortic. Sci. 2002, 127, 825-830. [CrossRef]

28. Greer, D.H.; Cirillo, C.; Norling, C.L. Temperature-dependence of carbon acquisition and demand in relation to shoot and fruit growth of fruiting kiwifruit (Actinidia deliciosa) vines grown in controlled environments. Func. Plant Biol. 2003, 30, 927-937. [CrossRef] [PubMed]

29. Minchin, P.E.H.; Snelgar, W.P.; Blattmann, P.; Hall, A.J. Competition between fruit and vegetative growth in Hayward kiwifruit. N. Z. J. Crop Hortic. Sci. 2010, 38, 101-112. [CrossRef]

30. Lopresti, J.; Goodwin, I.; Stefanelli, D.; Holford, P.; McGlasson, B.; Golding, J. Understanding the factors affecting within-tree variation in soluble solids concentration in peaches and nectarines. In Xxix International Horticultural Congress on Horticulture: Sustaining Lives, Livelihoods and Landscapes: International Symposia on the Physiology of Perennial Fruit Crops and Production Systems and Mechanisation, Precision Horticulture and Robotics; Tustin, D.S., Van Hooijdonk, B.M., Eds.; International Society for Horticultural Science Acta Horticulturae: Leuven, Belgium, 2016; Volume 1130, pp. 249-256.

31. Nardozza, S.; Boldingh, H.L.; Kashuba, M.P.; Feil, R.; Jones, D.; Thrimawithana, A.H.; Ireland, H.S.; Philippe, M.; Wohlers, M.W.; McGhie, T.K.; et al. Carbon starvation reduces carbohydrate and anthocyanin accumulation in red-fleshed fruit via trehalose 6-phosphate and MYB27. Plant Cell Environ. 2020, 43, 819-835. [CrossRef]

32. Gray, J.D.; Coombe, B.G. Variation in Shiraz berry size originates before fruitset but harvest is a point of resynchronisation for berry development after flowering. Aust. J. Grape Wine Res. 2009, 15, 156-165. [CrossRef]

33. Cerri, M.; Rosati, A.; Famiani, F.; Reale, L. Fruit size in different plum species (genus Prunus L.) is determined by post-bloom developmental processes and not by ovary characteristics at anthesis. Sci. Hortic. 2019, 255, 1-7. [CrossRef]

34. Blanke, M.M.; Lenz, F. Fruit photosynthesis. Plant Cell Environ. 1989, 12, 31-46. [CrossRef]

35. Brundell, D.J. Flower development of the chinese gooseberry (Actinidia chinensis Planch.) I. Development of the flowering shoot. N. Z. J. Bot. 1975, 13, 473-483. [CrossRef]

36. Srinivasan, C.; Mullins, M.G. Reproductive anatomy of grape-vine (Vitis Vinifera L): Origin and development of anlage and its derivatives. Ann. Bot. 1976, 38, 1079-1084. [CrossRef]

37. Holzapfel, B.P.; Smith, J.P.; Field, S.K.; Hardie, W.J. Dynamics of carbohydrate reserves in cultivated grapevines. Hortic. Rev. 2010, $37,143-211$.

38. Richardson, A.C.; Boldingh, H.L.; Kashuba, M.P.; Nardozza, S.; Greer, D.H. Kiwifruit reserves: Balancing vine growth and fruit productivity. Acta Hortic. 2018, 1218, 163-169. [CrossRef]

39. Greer, D.H.; Sicard, S.M. The net carbon balance in relation to growth and biomass accumulation of grapevines (Vitis vinifera cv. Semillon) grown in a controlled environment. Func. Plant Biol. 2009, 36, 645-653. [CrossRef]

40. Foster, T.M.; Seleznyova, A.N.; Barnett, A.M. Independent control of organogenesis and shoot tip abortion are key factors to developmental plasticity in kiwifruit (Actinidia). Ann. Bot. 2007, 100, 471-481. [CrossRef]

41. Seleznyova, A.N.; Thorp, T.G.; Barnett, A.M.; Costes, E. Quantitative analysis of shoot development and branching patterns in Actinidia. Ann. Bot. 2002, 89, 471-482. [CrossRef]

42. Seleznyova, A.N.; Greer, D.H. Effects of temperature and leaf position on leaf area expansion of kiwifruit (Actinida deliciosa) shoots: Development of a modelling framework. Ann. Bot. 2001, 88, 605-615. [CrossRef]

43. Clearwater, M.J.; Seleznyova, A.N.; Thorp, T.G.; Blattmann, P.; Barnett, A.M.; Lowe, R.G.; Austin, P.T. Vigor-controlling rootstocks affect early shoot growth and leaf area development of kiwifruit. Tree Physiol. 2006, 26, 505-515. [CrossRef]

44. Sale, P.R.; Lyford, P.B. Cultural, management and harvesting practices for kiwifruit in New Zealand. In Kiwifruit: Science and Management; Warrington, I.J., Weston, G.C., Eds.; Ray Richards Publisher: Auckland, New Zealand, 1990.

45. Greer, D.H. Photon flux density dependence of carbon acquisition and demand in relation to shoot growth of kiwifruit (Actinidia deliciosa) vines grown in controlled environments. Aust. J. Plant Physiol. 2001, 28, 111-120. [CrossRef]

46. Sepulveda, G.R.; Kliewer, W.M. Estimation of leaf area of two grapevine cultivars (Vitis vinifera L.) using laminae linear measurements and fresh weight. Am. J. Enol. Vitic. 1983, 34, 221-226.

47. Petrie, P.R.; Trought, M.C.T.; Howell, G.S.; Buchan, G.D.; Palmer, J.W. Whole-canopy gas exchange and light interception of vertically trained Vitis vinifera L. under direct and diffuse light. Am. J. Enol. Vitic. 2009, 60, 173-182. 
48. Greer, D.H.; Weedon, M.M.; Weston, C. Reductions in biomass accumulation, photosynthesis in situ and net carbon balance are the costs of protecting Vitis vinifera 'Semillon' grapevines from heat stress with shade covering. AoB Plants 2011, 2011 , plr023. [CrossRef]

49. Seal, A.G.; Dunn, J.K.; De Silva, H.N.; McGhie, T.K.; Lunken, R.C.M. Choice of pollen parent affects red flesh colour in seedlings of diploid Actinidia chinensis (kiwifruit). N. Z. J. Crop Hortic. Sci. 2013, 41, 207-218. [CrossRef]

50. Richardson, A.C.; Boldingh, H.L.; McAtee, P.A.; Gunaseelan, K.; Luo, Z.W.; Atkinson, R.G.; David, K.M.; Burdon, J.N.; Schaffer R.J. Fruit development of the diploid kiwifruit, Actinidia chinensis 'Hort16A'. BMC Plant Biol. 2011, 11, 1-14. [CrossRef] [PubMed]

51. Hopkirk, G.; Beever, D.J.; Triggs, C.M. Variation in soluble solids concentration in kiwifruit at harvest. N. Z. J. Agric. Res. 1986, 29, 475-484. [CrossRef]

52. Burdon, J.; Pidakala, P.; Martin, P.; Billing, D. Softening of 'Hayward' kiwifruit on the vine and in storage: The effects of temperature. Sci. Hortic. 2017, 220, 176-182. [CrossRef]

53. González, I.; Cao, K.L.; Davis, M.J.; Déjean, S. Visualising associations between paired 'omics' data sets. BioData Min. 2012 , 5, 19. [CrossRef]

54. R Core Team. R: A Language and Environment for Statistical Computing; R Foundation for Statistical Computing: Vienna, Austria, 2020.

55. Rohart, F.; Gautier, B.; Singh, A.; Le Cao, K.-A. mixOmics: An R package for 'omics feature selection and multiple data integration. PLoS Comp. Biol. 2017, 13, e1005752. [CrossRef]

56. Piller, G.J.; Meekings, J.S. The acquisition and utilization of carbon in early spring by kiwifruit shoots. Ann. Bot. 1997, 79, 573-581. [CrossRef]

57. Greer, D.H.; Jeffares, D. Temperature-dependence of carbon acquisition and demand in relation to shoot growth of kiwifruit (Actinidia deliciosa) vines grown in controlled environments. Aust. J. Plant Physiol. 1998, 25, 843-850. [CrossRef]

58. Clearwater, M.J.; Lowe, R.G.; Hofstee, B.J.; Barclay, C.; Mandemaker, A.J.; Blattmann, P. Hydraulic conductance and rootstock effects in grafted vines of kiwifruit. J. Exp. Bot. 2004, 55, 1371-1382. [CrossRef] [PubMed]

59. Greer, D.H. Photosynthetic development in relation to leaf expansion in kiwifruit (Actnidia deliciosa) vines during growth in a controlled environment. Aust. J. Plant Physiol. 1996, 23, 541-549.

60. Kriedemann, P.E. Photosynthesis in vine leaves as a function of light intensity, temperature and leaf age. Vitis 1968, 7, 213-220.

61. Jo, Y.-S.; Cho, H.-S.; Liu, I.-S.; Kim, W.-S. Comparative photosynthetic characteristics among major Actinidia species. Acta Hortic. 2008, 773, 271-276.

62. Chartzoulakis, K.; Therios, I.; Noitsakis, B. Effects of shading on gas-exchange, specific leaf weight and chlorophyll content in 4 kiwifruit cultivars under field conditions. J. Hortic. Sci. 1993, 68, 605-611. [CrossRef]

63. Greer, D.H.; Seleznyova, A.N.; Green, S.R. From controlled environments to field simulations: Leaf area dynamics and photosynthesis of kiwifruit vines (Actinidia deliciosa). Func. Plant Biol. 2004, 31, 169-179. [CrossRef]

64. Petrie, P.R.; Trought, M.C.T.; Howell, G.S. Influence of leaf ageing, leaf area and crop load on photosynthesis, stomatal conductance and senescence of grapevine (Vitis vinifera L. cv. Pinot noir) leaves. Vitis 2000, 39, 31-36.

65. Black, M.Z.; Patterson, K.J.; Gould, K.S.; Clearwater, M.J. Physiological responses of kiwifruit vines (Actinidia chinensis Planch. var. chinensis) to trunk girdling and root pruning. N. Z. J. Crop Hortic. Sci. 2012, 40, 31-41. [CrossRef]

66. Genard, M.; Baret, F.; Simon, D. A 3D peach canopy model used to evaluate the effect of tree architecture and density on photosynthesis at a range of scales. Ecol. Model. 2000, 128, 197-209. [CrossRef]

67. Chaumont, M.; Morot-Gaudry, J.F.; Foyer, C.H. Seasonal and diurnal changes in photosynthesis and carbon partitioning in Vitis vinifera leaves in vines with and without fruit. J. Exp. Bot. 1994, 45, 1235-1243. [CrossRef]

68. Niinemets, U.; Garcia-Plazaola, J.; Tosens, T. Photosynthesis in leaf development and ageing. In Terrestrial Photosynthesis in a Changing Environment: A Molecular, Physiological, and Ecological Approach; Flexas, J., Loreto, F., Medrano, H., Eds.; Cambridge University Press: Cambridge, UK, 2012; pp. 353-372.

69. Chartzoulakis, K.S.; Therios, I.N.; Misopolinos, N.D.; Noitsakis, B.I. Growth, ion content and photosynthetic performance of salt-stressed kiwifruit plants. Irrig. Sci. 1995, 16, 23-28. [CrossRef]

70. Black, M.Z.; Patterson, K.J.; Minchin, P.E.H.; Gould, K.S.; Clearwater, M.J. Hydraulic responses of whole vines and individual roots of kiwifruit (Actinidia chinensis) following root severance. Tree Physiol. 2011, 31, 508-518. [CrossRef] [PubMed]

71. Clearwater, M.J.; Blattmann, P.; Luo, Z.; Lowe, R.G. Control of scion vigour by kiwifruit rootstocks is correlated with spring root pressure phenology. J. Exp. Bot. 2007, 58, 1741-1751. [CrossRef]

72. Snowball, A.M. Seasonal cycle of shoot development in selected Actinidia species. N. Z. J. Crop Hortic. Sci. 1997, 25, 221-231. [CrossRef]

73. Greaves, A.J.; Henton, S.M.; Piller, G.J.; Meekings, J.S.; Walton, E.F. Carbon supply from starch reserves to spring growth: Modelling spatial patterns in kiwifruit canes. Ann. Bot. 1999, 83, 431-439. [CrossRef]

74. Basile, B.; Giaccone, M.; Shahak, Y.; Forlani, M.; Cirillo, C. Regulation of the vegetative growth of kiwifruit vines by photo-selective anti-hail netting. Sci. Hortic. 2014, 172, 300-307. [CrossRef]

75. Brundell, D.J. Flower development of the chinese gooseberry (Actinidia chinensis Planch.) II. Development of the flower bud. N. Z. J. Bot. 1975, 13, 485-496. [CrossRef] 